\title{
Gastronomi: Disiplinler Arası Bir Buluşma
}

Türkiye'de devlet ve vakıf üniversiteleri çatısı altında Turizm Fakültesi, Güzel Sanatlar, Sanat ve Tasarım Fakülteleri ve Uygulamalı Bilimler Yüksekokulları bünyesinde yapılandırılmış olan dört yıllık Gastronomi ve Mutfak Sanatları lisans eğitimi, aday öğrenciler tarafından her sene gittikçe yükselen bir oranla tercih edilen bir programdır. İlk olarak 2003 yılında Yeditepe Üniversitesi Güzel Sanatlar Fakültesi'nde açılan program, bugün Türkiye ve Kuzey Kıbrıs'ta yetmiş sekiz örneğe ulaşmıştır. Özellikle son yıllarda hem vakıf hem de devlet üniversitelerinde Gastronomi ve Lisans programları sayıca çok büyük bir artış göstermiştir. Bugüne kadar Türkiye'deki Gastronomi ve Mutfak Sanatları lisans eğitimiyle ilgili olarak eğitimin içeriği ve niteliğini, eğitimde karşılaş1lan zorlukları ve eğitimin çıktılarını sorgulayan ve inceleyen farklı çalışmalar yapılmıştır (Öney 2016; Arıkan, Sürücü ve Arman 2018; Tütüncü 2019; Yaman ve Bulduk 2019; Seyitoğlu 2019). Bu çalışmaların birçoğunun giriş bölümünde öncelikle gastronomi terimi bir kavram olarak açıklanır. Günümüz Türkiye'sinde hem popüler kültürde hem de akademik dünyada tam olarak anlaşılmayan ve tanımı üzerinde mutabık kalınmayan bir anlama sahiptir gastronomi, bu anlamda tanıma halen muhtaç bir kavramdır. En dar anlamda, sözlüklerde ifade ediliş şekliyle "iyi yemek yeme sanatı ve/veya bilimidir" (Tütüncü 2019). Bu ifade biraz daha seçkinci bir anlam taşır ve tadımcı olabilme yolunda gastronomiyi bir araç olarak değerlendirir. Diğer bir tanım benzer bir ifade olsa da daha kapsayıcıdır: "gastronomi yiyecek ve yeme-içme bilimidir ve bu bağlamda sanat ve kültür felsefesiyle ilintilidir." (Öney 2016). Bu tanım çok daha geniş ve derin bir anlam yükler gastronomiye. "Gastronomi disiplinler arası bir doğaya sahiptir ve farklı anlamlar içerir fakat odaklandığı bir araştırma sorunsalı yoktur ve bu durum gastronomiyi bir disiplin olmaktan uzaklaştırır" fikri bir başka çalışmada yer alır. (Seyitoğlu 2019). Gastronomi tanımlanması güç bir terim, kavram olsa da akademik anlamda yabancı literatür incelendiğinde anlamı açık bir şekilde ortaya konulabilir. Gastronomi ve Mutfak Sanatları alanında lisans ve lisansüstü eğitiminin niteliği ve içeriği kurgulanırken akademik olarak gastronomi kavramını tam olarak anlamak önemlidir. Gastronomi sadece yemek, yemek pişirmek, yemeği tat açısından değerlendirmek veya iyi yemek sanatı anlamlarını kapsamaz. Esasen yemek pişirme eylemi, pişirme teknikleri doğrudan "mutfak sanatları" terimiyle ilişkilidir. Özellikle Amerika Birleşik Devletleri'nde "mutfak sanatları (culinary arts)" ifadesi aşçllık ve restoran işletmeciliği eğitimi verilen ön lisans ve lisans programlarını tanımlar. Gastronomi terimi, yeme-içme eylemine daha kavramsal bir bakış açısı sunan holistik bir penceredir. İşte tam bu sebepten ötürü gastronomi ve mutfak sanatları terimleri birlikte kullanılarak Türkiye'de lisans programlarının içeriği yapılandırılmalıdır. Aslında bu iki farklı ifadeyi bir arada kullanarak yüksek öğretimde bir model sunan Türkiye bir anlamda dünyada bir öncülük yapmıştır. Bugün dünyada örneğin İspanya'da, aynı adla ifade edilen lisans programları bulunmaktadır. Türkiye'de akademik olarak gastronomi en çok turizm çerçevesi içinde anlamlandırılarak araştırmalara konu olmuştur. Nitekim son yapılan bir çalışmanın gösterdiği gibi lisansüstü çalışmalarda gastronomi alanında bugüne kadar 
Türkiye'de yapılan araştırmalar daha çok tek bir yöne, gastronomi turizmine doğru eğrilmiştir (Altaş ve Acar 2018). Aslen gastronomi kavramının bütünleşik ve holistik yapısının anlaşılması, alanda literatüre katkıda bulunacak özgün nitelikte akademik çalışmalara yön vermesi açısından çok önemlidir.

Yazılı birçok mecrada dile getirildiği gibi etimolojik olarak Yunanca mide anlamina gelen gastèr ve yasa anlamına gelen nomos kelimelerinin bileşiminden oluşan gastronomi teriminin ilk olarak M.Ö. dördüncü yüzyılda yaşamış olan şair Archestratus'un yazınında geçtiği kabul edilir. Archestratus'un satırlarında "mide yasası" anlamına gelen gastronomi "iyi yemek pişirmek", "sofra keyfi" ve "iyi yeme ve içme sanatı" anlamina gelir (Csergo 2016; Perullo 2018). Daha sonra 19. yüzyıl Fransa'sina kadar gastronomi bir terim olarak yaygin olarak kullanılmaz. Türkiye'de son yıllarda yemek meraklılarının, yeme-içme sektöründe çalışanların ve medyanın anlamını tam olarak tartmadan gündelik hayatta sıklıkla kullandıkları gastronomi terimi, Fransızcadan Türkçeye 1990'lı yıllardan sonra geçen yeni bir kelimedir. Türk Dil kurumunun sözlügünde gastronomi iki tanımla betimlenir: "Yemeği iyi yeme merakı", ve ikinci olarak "sağllğa uygun, iyi düzenlenmiş, hoş ve lezzetli mutfak, yemek düzeni ve sistemi". Gastronomi terimi bu anlamda kimilerine göre özenli, şık hazırlanmış sofralarda paylaşılan lezzetli ve rafine yiyecek ve içecekleri, kimilerine göre iyi yemek pişirme sanatını ifade eder. Esasen bu tanımların hepsi gastronomi terimini tam olarak açıklamaya yeterli olmaz, zira gastronomi kavramsal olarak çok daha geniş ve kapsamlı bir anlam içerir.

18. yüzyılda yaşamış olan Fransız hukukçu ve politikacı Brillat-Savarin (1755-1826) ölümünden iki ay önce 1825 'te yayınladı̆̆ 1 meşhur Physiologie du Goût (Tadın Fizyolojisi) adlı kitabında gastronomi kelimesini uzun uzun tanımlayarak açıklar (Brillat-Savarin 1982). Gastronomi söyleminin kurucusu olarak kabul edilen Brillat-Savarin "gastronomi insanın beslenmesiyle ilgili olan her şeyin zihinsel bilgisini kapsar" diye ifade eder. Ona göre gastronominin amacı "insan için gerekli olan en üstün, olası beslenme biçimini tavsiye ederek onun korunmasına özen göstermektir". Gastronomi besin maddelerini tanımladığı ve sınıflandırdığ 1 için coğrafya ve tarihin; gıda maddelerinin bileşimi ve özelliklerini inceleyip analizini yaptığı için fizik ve kimyanın; yemekleri uyarlayarak tat duygusuna haz verecek hale getirdiği için aşçlık sanatının; en iyi ürünü en hesaplı fiyata alarak karlı biçimde satma yöntemlerini aradığ parçasıdır. Gastronomi yenilebilir ve içilebilir her şeyi içerir bununla ilgili olarak tarımı, ticareti ve endüstriyi de kapsar. Gastronomi ayrıca yiyeceklerin insan bedeni üzerindeki etkilerini ve zihinsel olarak yemek çevresinde ürettiği alg1, değer ve anlamları da değerlendirir (Açıkkol 2006).

Brillat-Savarin'in gastronomi tanımını içeren çok erken bir tarihte yaptığı bu detaylı açıklamalar, günümüzde akademik anlamda gastronomiyi nasıl tanımlamamız gerektiği yolunda bize ışık tutar. Gastronomi bu bağlamda sadece iyi yemek arayışını, iyi ve lezzetli yemeğe değer vermeyi kapsamaz. Gastronomi gidanın en ham halinden dönüştürülüp tüketim için hazır bir ürün haline getirilmesine, tüketilmesine ve hatta tüketimden sonraki süreci de kapsar. Bu bağlamda gastronomi coğrafya, tarım, etnobotanik, ziraat, ekonomi, aşçılık, işletme, gıda bilimi, kimya ve beslenme bilimini; tüketim şekilleri, zihinsel algılar ve kültür bağlamında psikoloji, sanat, tarih, sosyoloji ve antropoloji gibi birçok disiplinden beslenen bir alandır. Bu bağlamda gastronomi doğası itibariyle hem araştırmaciya hem de öğrenciyi disiplinler arası bir yolculuğa davet eder. Sosyal ve/veya pozitif bilimlerin teori ve kuramları aracılığıyla incelenmesi gereken gastronomi, duyulara hitap eden yönüyle pratik olan uygulamalarda hayat bulur. Dolayısiyla gastronomi sadece seçkin, rafine lezzetlerin arandığ 1 ve tüketildiği bir alanı kapsamaz kültürlere göre değişkenlik gösteren tüketim alışkanlıklarının insanoğlu için en faydalı ve en iyi hallerini araştırır, üretir ve üzerinde düşündürerek açıklar. Bu bağlamda gastronomi sadece hünerli parmakların ürettiği lezzetli yiyecekler değil, düşünen ve araştıran zihinlerin kalemle aktardığı bilgiler bütünüdür. Yiyeceğin hem bilimsel hem de kültürel tüm kodlarını somut örnekler aracılığıyla açıklamayı hedefleyen bir alandır. 
Son on yılda en başta Amerika Birleşik Devletlerinde, sosyal bilimlerde akademik olarak gıdayla ilgili yapılan çalışmalar için ortak olarak kullanılan yeni bir kavram oluşmuştur: "Yeme-İ̧̇me Çalışmaları (Food Studies)". Food Studies antropoloji, sosyoloji, tarih, siyaset bilimi, turizm, iletişim, arkeoloji, dilbilim, psikoloji, işletme, ekonomi gibi sosyal bilimlerin gözünden her disipline özgü araştırma tekniğiyle gıdayla ilgili yapılan çalışmaları kapsar. Food Studies esas olarak gidanın üretimden tüketime kadar olan yolculuğunu sosyal ve kültürel kodları irdeleyerek inceler (Neill ve arkadaşları 2017). Gıdanın kimya, teknoloji, beslenme ve ziraat alanlarıyla ilgili olarak akademik çalışmalar bir alan oluşturmuş olduğu için food studies daha çok sosyal bilimler gözüyle eksik kalan bakışı geliştirir. Fakat pozitif bilimlerin bakış açısını ret etmez aksine ortak bakış açısıyla yapılan çalışmaları destekler. Yüksek öğretim alanıyla ilgili olarak ABD'deki örnekler Food Studies alanının daha çok lisansüstü programlarında oluşturulduğunu gösterir. Fakat sadece gastronomi ifadesi kullanılarak da kurgulanmış olan lisansüstü programları da vardır. Gastronomi ve Food Studies kavramları çok benzer ve farkları oldukça azdır. İki kavramın arasındaki ortaklık ve farklılıkları inceleyen bir makalede yazarlar sonuç olarak şu önermeyi yaparlar: "Gastronomi, kültürü anlamayı çalışan yeme-içme çalışmalarının bir penceresidir" (Neill ve arkadaşları 2017). Kısaca gastronomi doğrudan yiyecek ve içecekle ilgilenir ve onun kültürle olan bağına bakar; food studies ise gıdayı kültürü anlamak için irdeler. Bu açılamaya bir ek yapmak gerekebilir. Gastronomi ve food studies arasındaki bir başka fark da gastronomide yiyecek ve içeceğin beslenme bilimi ve/veya gıda bilimi açısından da incelenmesidir. Yemek bilimi olarak çevirebileceğimiz culinary science kavramı tam olarak bu noktada anlaşılması gereken önemli bir kavram olarak belirir. Culinology yemek bilimi için kullanılan yeni bir terimdir. Gida bilimi ve mutfak sanatları alanlarının birleşiminden doğan bir ifade olarak ABD de kullanılmaktadır (Cheng ve arkadaşları 2011). Yiyecek-içecek, pişirme ve gıda hazırlama teknikleri arkasındaki bilimi anlamayı hedefleyen bu kavram gastronomi alanının önemli bir parçasıdır.
Türkiye'de gastronomi alanında özgün akademik çalışmalara imza atabilmek için Food Studies ve Culinary Science kavramlarının anlaşılması önemlidir. Food studies penceresinden bakarak sosyoloji, antropoloji, turizm, siyaset bilimi, dilbilim, halkbilimi, tarih gibi sosyal bilimlerin gastronomi alanıyla ilgili olarak yaptıkları araştırmalar dikkate alınarak ve her disipline özgü araştırma tekniklerini kullanılarak gastronomi ve mutfak sanatları alanındaki lisansüstü çalışmalar alana yepyeni bilimsel katkılar sunan çıtılar sunabilir. Aynı şekilde yemek bilimi (culinary science) penceresinden bakarak yiyecek hazırlama, pişirme ve saklama teknikleri üzerine de çalışılabilir. $\mathrm{Bu}$ bağlamda gastronomi ve mutfak sanatları lisansüstü çalışmalarında öğrencilerin farklı disiplinlerde yapılan ve yabancı dilde yayımlanan literatüre hakim olmaları da elzemdir. Öte yandan gastronomi ve mutfak sanatları alanında görev yapan biz akademisyenler de kendi formasyonlarımıza göre uygun olan araştırma tekniklerini kullanarak, bireysel veya ortak özgün çalışmalar gerçekleştirebiliriz. Aslında gastronomi alanının sunduğu en güzel olanak farklı disiplinlerin araştırma tekniklerini kullanarak ortak çalışmalar yapabiliyor olmaktır.

Disiplinler arası bir bakış açısı getiren gastronomi kavramının kavranması lisans eğitim programlarının müfredatları kurgulanırken son derece önemlidir. Gastronomi ve Mutfak Sanatları lisans programları yiyecek ve içecekle ilgili olarak hem pratik hem de teorik dersleri içermektedir. Mutfak Sanatları kısmı aşçılık ve restoran yönetimi alanındaki uygulamalı dersleri kapsarken; gastronomi alanı yiyecek ve içecekle ilgili olarak teorik alanları kapsar. Gida ve mutfak bilimi, beslenme, ekonomi, turizm, tarih, sanat, antropoloji ve/veya tasarım alanlarında verilen dersler öğrencilerin pratik uygulamalarda ihtiyaçları olan alt yapıyı sağladığı gibi aynı zamanda eleştirel düşünme, problem çözümü ve yaratıcılık alanlarında da gelişimlerini sağlar. Gastronomi ve Mutfak Sanatları eğitiminin disiplinler arası bir eğitim paketiyle ele alınması, aşçılık eğitiminde mesleki eğitimden bilişsel eğitime geçişi sağlar. (Hegarty 2011). Bilimsel akılcı bilgiyle sanatsal ruhu birleştirerek, öğrencilerin mutfak sanatları 
alanındaki yaratıcılıklarını artırır (Jeou-Shyan ve Lee 2010). Profesyonel bilgi, bilim, sanat ve kültür şef adaylarının yaratıcılıklarını ve girişimcilik ruhlarını besler. Örneğin öğrenciler mutfak bilimi (culinary science) bilgisiyle pişirme tekniklerini mükemmelleştirir, duyusal analizle yiyecek ve içecek üretimini iyileştirebilirler. Ziraat, beslenme, ekonomi ve etnobotanik bilgisiyle gida sisteminde sürdürülebilir modeller önerebilir; antropoloji ve sosyoloji bilgileriyle bireylerin ve toplumların beslenme alışkanlıklarını anlamlandırırlar. Tarih ve arkeoloji aracılığıyla gastronomi mirasını keşfederek sürdürülebilir beslenme modelleri önerirler ve son olarak sanat ve tasarım aracılığıyla mesleki anlamda ihtiyaçları olan yaratıcılık kanallarını beslerler.

\section{KAYNAKÇA}

Altaş, A ve Acar, Y. (2018). Bibliometric Profile of the Postgraduate Dissertations Written in the Field of Gastronomy, Aksaray Üniversitesi Iktisadi ve İdari Bilimler Fakültesi Dergisi, 10 (3): 1-10.

Arıkan, E., Sürücü, Ö.A. ve Arman, A. (2018). Yükseköğretim Kurumlarındaki Eğitim Mutfaklarında Karşılaşılan Sorunlar ve Çözüm Önerileri, Journal of Tourism and Gastronomy Studies, 6 (2): 592-601.

Brillat- Savarin, J. A. (2006). Gastronomi Üzerine, Yemek ve Kültür, Ö. Açıkkol. (çev), 6: 16-21.

Cheng, M., Ogbeide, G. A. ve Hamouz, F. L. (2011). The Development of Culinary Arts and Food Science into a New Academic Discipline- Culinology, Journal of Culinary Science \& Technology, 9 (1): 17-26.

Csergo, J. (2016). La Gastronomie est-elle Une Marchandise Culturelle Comme Une Autre? Chartres: Menufretin.

Jeou-Shyan ve Lee, H. Y. (2010). What Does it Take to Be a Creative Culinary Artist?, Journal of Culinary Science and Technology, 5 (2-3): 5-22.

Hegarty, J. (2011). Achieving Excellence by Means of critical Reflection and Cultural Imagination in Culinary Arts and Gastronomy Education, Journal of Culinary Sciences and Technology, 9 (2): 55-65.

Hegarty, J. (2005), Developing "Subjects Fields" in Culinary Arts, Science, and Gastronomy, Journal of Culinary Science and Technology, 4 (1): 5-13.
Hegarty, J. A. ve O'Mahony, G. B. (1999), Gastronomy: A Phenomenon of Cultural Expressionism and an Aesthetic for Living, Journal of Hospitality \& Tourism Education, 11 (4): 25-29.

Hertzman, J. L. (2008). A Suggested Curriculum for Associate Degree Culinary Arts Programs, Journal of Culinary Science and Techonology, 6 (4): 256-278.

Öney, H. (2016). Gastronomi Eğitimi Üzerine Bir Değerlendirme, Selçuk Üniversitesi Sosyal Bilimler Enstitüsü Dergisi, 35: 193-203.

Maberly, C. ve Reid, D. (2014). Gastronomy: An Approach To Studying Food, Nutrition \& Food Science, 44 (4): 272278.

Miller, J. ve Deutsch, J. (2010). Food Studies: An Introduction to Research Methods. Oxford: Berg.

Neill, L., Poulston, J., Hemmington, N., Hall, C. ve Bliss, S. (2017). Gastronomy or Food Studies: A Case of Academic Distinction, Journal of Hospitality \& Tourism Education, 29 (2): 91-99.

Ory, P. (1998), Le Discours Gastronomique Français. Paris: Gallimard.

Perullo, N. (ed) (2018). University of Gastronomic Sciences Pollenzo Manifesto. İtalya.

Santich, B. (2004). The Study Of Gastronomy And Its Relevance To Hospitality Education And Training, International Journal of Hospitality Management, 23 (1).

Sarışık, M. ve Özbay, G. (2015). Gastronomi Turizmi Üzerine Bir Literatür İncelemesi, Anatolia: Turizm Araştırmaları Dergisi, 26 (2): 264-278.

Seyitoğlu, F. (2019). Defining the Current Position of the Gastronomy Field in Turkey, Journal of Culinary Science E Technology, DOI: 10.1080/15428052.2019.1692746.

Tütüncü, Ö. (2019). Lisans Eğitiminde Mutfak Zanaatları ve Gastronomi, Anatolia Turizm Araştırmaları Dergisi, 30 (1): 93-97.

Yaman, Z.Ö. ve Bulduk, S. (2019). Gastronomi ve Mutfak Sanatları Eğitiminin Kalite Göstergeleri Açısından Değerlendirilmesi, Business Management Studies: An International Journal, 7 (5): 2770-2804.

Özge SAMANCI, Doç. Dr., Özyeğin Üniversitesi, Uygulamalı Bilimler Yüksekokulu, Gastronomi ve Mutfak Sanatları Bölümü, Çekmeköy Kampüsü, Nişantepe Mah. Orman Sok. 34794 Çekmeköy, İstanbul.

E-posta: ozge.samanci@ozyegin.edu.tr

ORCID: 0000-0001-6539-8468. 